\title{
Expression of Concern: AFLP-Based Analysis of Genetic Diversity, Population Structure, and Relationships with Agronomic Traits in Rice Germplasm from North Region of Iran and World Core Germplasm Set
}

\author{
Karim Sorkheh ${ }^{1} \cdot$ Mohammad Masaeli $^{2} \cdot$ Maryam Hosseini Chaleshtori $^{3}$. \\ Asfaw Adugna ${ }^{4} \cdot$ Sezai Ercisli ${ }^{5}$
}

Published online: 1 August 2019

(c) Springer Science+Business Media, LLC, part of Springer Nature 2019

The Editor-in-Chief and the publisher are issuing an editorial expression of concern because the validity of the content of this article (Sorkheh et al. 2016) cannot be verified. There is a strong reason to believe that the peer-review process was compromised. Investigation into these concerns could neither be confirmed nor be refuted. All authors agree with the publication of this Expression of Concern.

\section{Reference}

Sorkheh K, Masaeli M, Chaleshtori MH et al (2016) Biochem Genet 54:177. https://doi.org/10.1007/ s10528-016-9711-7

Publisher's Note Springer Nature remains neutral with regard to jurisdictional claims in published maps and institutional affiliations.

The online version of the original article can be found under https://doi.org/10.1007/10528-0169711-7.

Karim Sorkheh

karimsorkheh@gmail.com

1 Department of Agronomy and Plant Breeding, Faculty of Agriculture, Shahid Chamran University of Ahvaz, P. O. Box 61355/144, Ahvaz, Iran

2 Department of Agronomy and Biotechnology, Faculty of Agriculture, University of Guilan, P.O. Box 41635/3988, Rasht, Iran

3 Rice Research Institute of Iran, P. O. Box 1658, Rasht, Iran

4 Melkassa Agricultural Research Center, P.O. Box 1085, Adama, Ethiopia

5 Department of Horticulture, Agricultural Faculty, Ataturk University, 25240 Erzurum, Turkey 